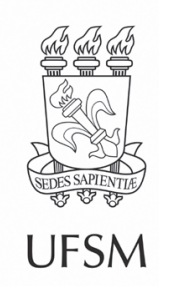

\title{
Artigos
}

\section{Enraizamento de Sequoia sempervirens (Cupressaceae) em função do padrão de miniestacas, substratos e regulador de crescimento}

\author{
Rooting of Sequoia sempervirens in function of the pattern of \\ minicuttings, substrates and use of growth regulator

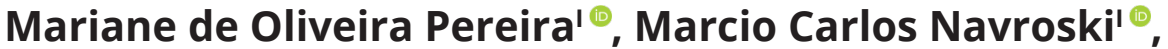 Alessandro Camargo Ângelo" ${ }^{\bullet}$, Gilmar Schafer ${ }^{\prime \prime \prime} \odot$, Ramon Silveira de Andrade ${ }^{\bullet}$, Carolina Moraes' ${ }^{\oplus}$, Gabriel de Souza' ${ }^{\oplus}$ \\ 'Universidade do Estado de Santa Catarina, Lages, SC, Brasil \\ "Universidade Federal do Paraná, Curitiba, PR, Brasil \\ "'Universidade Federal do Rio Grande do Sul, Porto Alegre, RS, Brasil
}

\begin{abstract}
RESUMO
Sequoia sempervirens (sequoia) é uma espécie conhecida pela qualidade superior de sua madeira, sendo a produção de mudas por miniestaquia uma alternativa viável. O objetivo do trabalho foi avaliar a posição de coleta, presença ou ausência de folhas aciculares em miniestacas e a produção de mudas cultivadas em diferentes substratos e utilização de AIB. Foram utilizadas miniestacas de diferentes clones, oriundas de minijardim clonal. Para o padrão de miniestacas utilizou-se a porção lignificada, com média lignificação e pouca lignificação, na presença ou ausência de folhas aciculares, avaliando-se um clone. Em relação aos substratos, observou-se o comportamento de três clones e quatro substratos de marcas comerciais. Para o emprego de regulador de crescimento utilizou-se um clone e diferentes concentrações de AIB (0,0 a $5000 \mathrm{mg} \mathrm{L-1})$. As miniestacas foram colocadas para enraizar em estufim e avaliadas aos 90 dias. Todos os experimentos foram instalados em delineamento inteiramente casualizado, com posterior avaliação da porcentagem de sobrevivência; porcentagem de miniestacas com calos; porcentagem de miniestacas enraizadas e número de raízes emitidas por miniestaca enraizada. Miniestacas pouco lignificadas (ápice) com folhas aciculares apresentaram os melhores resultados para sobrevivência (96\%) e enraizamento (94\%); miniestacas muito lignificadas sem folhas aciculares obtiveram baixo enraizamento (10\%). Houve considerável variação de enraizamento entre os substratos (66 a 100\%) e o número de raízes foi mais influenciado pelo clone utilizado. Os melhores resultados foram observados naqueles com componentes mais orgânicos. O emprego de AIB na miniestaquia não foi significativo para nenhuma das variáveis analisadas. Miniestacas coletadas em porções apicais e com presença de folhas aciculares mostraramse mais indicadas para trabalhos com a espécie. Para a seleção do melhor substrato deve-se observar o efeito clonal, priorizando-se substratos com composição mais orgânica. A utilização de AIB não influenciou positivamente o enraizamento de miniestacas, não sendo recomendado o seu uso.
\end{abstract}

Palavras-chave: Gymnospermae; Propagação vegetativa de conífera; Enraizamento adventício; AIB; Silvicultura clonal 


\section{ABSTRACT}

Sequoia sempervirens (sequoia) is a species known for the superior quality of its wood, making plants production by minicuttings a viable alternative. The objective of the work was to evaluate the position of collection, presence or absence of acicular leaves in minicuttings and production of plants grown on different substrates and use of IBA. Minicuttings from different clones, from a clonal minigarden, were used. For the minicuttings pattern, use a lignified portion, with medium lignification and little lignification, in the presence or absence of acicular leaves, available if a clone. Regarding substrates, the behavior of three clones and four substrates of commercial brands. For the growth regulator, was used a clone and different concentrations of IBA ( 0.0 to $\left.5000 \mathrm{mg} \mathrm{L}^{-1}\right)$. Minicuttings were placed to root in mini-tunnel and evaluated at 90 days. All experiments were installed in completely randomized design, with subsequent assessment of the percentage of survival; percentage of minicuttings with calluses; percentage of rooted minicuttings and number of roots emitted by rooted minicuttings. Little lignified minicuttings (apex) with acicular leaves, showed the best results for survival (96\%) and rooting (94\%); very lignified minicuttings without acicular leaves obtained low rooting (10\%). There was considerable variation in rooting between substrates (66 to 100\%) and the number of roots was more influenced by the clone used. The best results were observed in those with more organic components. The use of IBA in the minicutting was not significant for any of the variables analyzed. Minicuttings collected in apical portions and with the presence of acicular leaves are more suitable for work with a species. To select the best substrate, must be observe the clonal effect, prioritizing substrates with a more organic composition. The use of IBA did not positively influence or reduce minicuttings, it was not recommended or its use.

Keywords: Gymnospermae; Vegetative propagation of conifers; Adventitious rooting; IBA; Clonal forestry

\section{INTRODUÇÃO}

As atuais demandas produtivas, concentradas em algumas espécies florestais, revelam oportunidades para o trabalho com espécies alternativas, visando a um aumento da produção de madeira e abertura para novos mercados. Sequoia sempervirens (D. Don) Endl. (Cupressaceae), conhecida popularmente como sequoia, pode ser uma opção para trabalhos em que há exigência de qualidade superior da madeira. É uma conífera nativa da costa oeste do estado da Califórnia e costa sudoeste do estado do Oregon, nos Estados Unidos (OLSON; ROY; WALTERS, 1990).

Sequoia está entre as madeiras mais duradouras dos EUA, possuindo longa durabilidade natural, fácil de ser trabalhada e grã direita com baixa variação dimensional (retração e inchamento). A espécie possui um cerne de grandes proporções e seus extrativos tornam a madeira resistente ao ataque de fungos e insetos (UNITED STATES, 2010). 
Pereira, M. O.; Navroski, M. C.; Ângelo, A. C.; Schafer, G.; Andrade, R. S.; Moraes, C.; Souza, G. | 1260

A espécie apresenta ciclo longo e sua propagação por sementes demonstra baixas taxas de germinação (média de 10\%) e baixa viabilidade de plântulas (BOE, 1974). A propagação vegetativa pode ser uma alternativa para a obtenção de mudas de sequoia, por meio da utilização de técnicas variadas. Nos últimos anos, houve grandes avanços no desenvolvimento de sistemas operacionais de propagação vegetativa para espécies de coníferas. A estaquia é considerada o meio mais efetivo e operacionalmente disponível para multiplicar indivíduos específicos que possuem características desejáveis (LUNA, 2008).

A técnica de miniestaquia pode ser utilizada para várias espécies lenhosas de interesse florestal, pois, além dos incrementos em enraizamento, as miniestacas desenvolvem um sistema radicial de melhor qualidade em termos de vigor, uniformidade e volume, o que reflete positivamente na sobrevivência e desempenho da planta no campo (ALCANTARA et al., 2007).

Alguns fatores podem aumentar a eficiência dessa técnica, como a utilização de reguladores de crescimento vegetal (ALCANTARA et al., 2007), a escolha do tipo de miniestaca e do substrato empregado (PIMENTEL et al., 2016). Vários fatores afetam a formação de raízes, estando diretamente relacionados ao sucesso da produção de mudas via propagação vegetativa, como: condições fisiológicas da planta-matriz, balanço hormonal e a posição do propágulo na brotação (OLIVEIRA et al., 2016).

Conforme a posição de coleta das miniestacas no ramo é possível classificálas como apicais, intermediárias ou basais. O uso de diferentes tipos de miniestacas implica maior aproveitamento das brotações colhidas, aumentando a produtividade do minijardim (OLIVEIRA et al., 2016). O tipo de miniestaca utilizado vai influenciar no enraizamento, devendo-se observar a presença e o número de folhas, que constituem fonte de auxinas e carboidratos importantes no processo de enraizamento (HARTMANN et al., 2011). 
Além da preocupação com a posição de coleta e do tipo de miniestaca utilizado, também é importante considerar a utilização de um substrato adequado. O substrato utilizado para o enraizamento de estacas é um fator de grande importância na propagação vegetativa, sendo variável de acordo com a espécie a ser propagada e devendo permitir bom suprimento de oxigênio e água para a base da estaca. O substrato mais adequado deve ser inerte, poroso, com boa drenagem e capaz de manter a aeração e a umidade, permitindo o bom desenvolvimento do sistema radicial (OLIVEIRA et al., 2012).

Outro aspecto importante relacionado à composição do substrato é que as espécies arbóreas têm necessidades nutricionais e fisiológicas específicas, tornando importante a realização de estudos para definir o melhor substrato para propagação de cada espécie. Diversas são as opções de tipos de substrato, sendo os mais comuns nos viveiros de produção de mudas: areia, turfa, serragem semidecomposta, casca de arroz carbonizada, composto orgânico, terra de subsolo, fibras de coco, vermiculita e mistura entre eles (XAVIER; WENDLING; SILVA, 2013).

A utilização de um promotor de enraizamento também é um fator importante a ser considerado. À medida que a idade da planta doadora aumenta, a aplicação de auxinas pode maximizar o sucesso no enraizamento (LUNA, 2008). Aplicações de reguladores de crescimento aos propágulos vegetativos, principalmente auxinas, proporcionam maior porcentual, velocidade e qualidade de enraizamento. A auxina sintética mais utilizada para o enraizamento de estacas ou miniestacas é o ácido indolbutírico (AIB), apresentando diferentes resultados conforme a espécie, época do ano, concentração e condições ambientais (HARTMANN et al., 2011).

A partir disso, o objetivo deste trabalho foi avaliar a posição de coleta e presença ou ausência de folhas aciculares em miniestacas de Sequoia sempervirens, além da produção de mudas sob cultivo em diferentes substratos e utilização de AIB. 
Pereira, M. O.; Navroski, M. C.; Ângelo, A. C.; Schafer, G.; Andrade, R. S.; Moraes, C.; Souza, G. | 1262

\section{MATERIAIS E MÉTODOS}

\subsection{Fonte de material reprodutivo}

Como fontes de propágulos para a miniestaquia foram utilizadas minicepas de matrizes selecionadas de sequoia de aproximadamente 40 anos de idade, localizadas em São Francisco de Paula - RS, as quais foram propagadas pelo processo de estaquia convencional após 120 dias do anelamento parcial ou completo da árvore matriz. Esse material foi coletado nas árvores-matrizes e transportado até o Viveiro Florestal do Centro de Ciências Agroveterinárias (CAV) da Universidade do Estado de Santa Catarina - UDESC. Após, confeccionaram-se estacas com tamanho de $10 \mathrm{~cm}$, contendo um par de folhas aciculares reduzidas a 50 \% da área foliar e imersas em solução hidroalcóolica de AIB (6.000 $\left.\mathrm{mg} \mathrm{L}^{-1}\right)$ durante 10 segundos. Em seguida, foram inseridas em tubetes $\left(180 \mathrm{~cm}^{-3}\right)$ contendo vermiculita de granulometria média e substrato comercial (1:1 v/v) à base de turfa, casca de arroz carbonizada e calcário calcítico e dispostas em casa de vegetação para o enraizamento.

Após a estaquia, mudas enraizadas de cinco meses de idade foram aclimatadas em casa de sombra por 30 dias, sendo em seguida transferidas para casa de vegetação para completar a aclimatação por mais 30 dias. Posteriormente, mudas com aproximadamente $20 \mathrm{~cm}$ de altura foram transferidas para vasos com capacidade de $5 \mathrm{~L}$, preenchidos com substrato comercial (50\%) e vermiculita de granulometria média (50\%). Quinze dias após a instalação, tempo necessário para adaptação das mudas ao sistema, efetuou-se a poda do ápice da brotação principal das mudas a uma altura de $10 \mathrm{~cm}( \pm 2 \mathrm{~cm})$, formando-se assim as minicepas para o estabelecimento do minijardim clonal. Mensalmente, durante quatro meses, realizou-se poda de formação das minicepas.

A solução nutritiva utilizada no minijardim clonal foi à base do fertilizante comercial Forth Solúvel Inicial ${ }^{\circledR}$, composto por $10 \% \mathrm{~N}$ (solúvel em água); $42 \% \mathrm{P}_{2} \mathrm{O}_{5}$ 
(solúvel em água); 10\% $\mathrm{K}_{2} \mathrm{O}$ (solúvel em água); 0,6\% Mg; 0,1\% Fe e 0,02 Br. A fertirrigação era realizada duas vezes por semana, tendo cada minicepa recebido $50 \mathrm{~mL}$ da solução composta pela diluição de 1,5 gramas do fertilizante por litro de água. Após o período de formação das minicepas efetuou-se a coleta das brotações para a realização dos experimentos.

\subsection{Experimento I - padrão de miniestacas}

O experimento foi conduzido em delineamento inteiramente casualizado (DIC), com seis tratamentos (porção lignificada, com média lignificação e pouca lignificação; com ou sem folhas aciculares) (Figura 1), compostos por 13 repetições de seis miniestacas cada. Para isso, foi utilizando o clone A138, obtido do minijardim clonal, o qual foi produzido e conduzido conforme descrito anteriormente. Considerou-se como miniestacas lignificadas as localizadas nas porções basais que apresentam idades superiores, média lignificação em porções intermediárias e pouca lignificação em porções apicais.

Foram preparadas miniestacas com aproximadamente $10 \mathrm{~cm}$ de comprimento, sendo a porção basal cortada em bisel e a porção superior incisada transversalmente, com presença ou ausência de folhas aciculares. Nos tratamentos em que havia a presença de folhas, estas foram cortadas pela metade, à exceção das folhas presentes na parte apical das miniestacas pouco lignificadas.

Após preparadas, as miniestacas foram dispostas para enraizar em tubetes de $180 \mathrm{~cm}^{3}$ contendo vermiculita de granulometria média e substrato comercial (1:1 v/v), com a adição de $6 \mathrm{~g} \mathrm{~L}^{-1}$ de fertilizante de liberação controlada (18-05-09) com 5-6 meses de liberação. O substrato comercial foi composto por turfa, casca de arroz carbonizada, calcário calcítico, aditivado com N (0,04\%), $\mathrm{P}_{2} \mathrm{O}_{5}(0,04 \%)$ e $\mathrm{K}_{2} \mathrm{O}(0,05 \%)$ (característica físicas e químicas descritas em substrato I - Tabela 1). 
Figura 1 - Miniestacas na presença e ausência de folhas aciculares conforme posições estabelecidas, sendo: A. pouco lignificada com presença de folhas; B. média lignificação com presença de folhas; C. lignificada com presença de folhas; D. pouco lignificada com ausência de folhas; E. média lignificação com ausência de folhas; F. lignificada com ausência de folhas

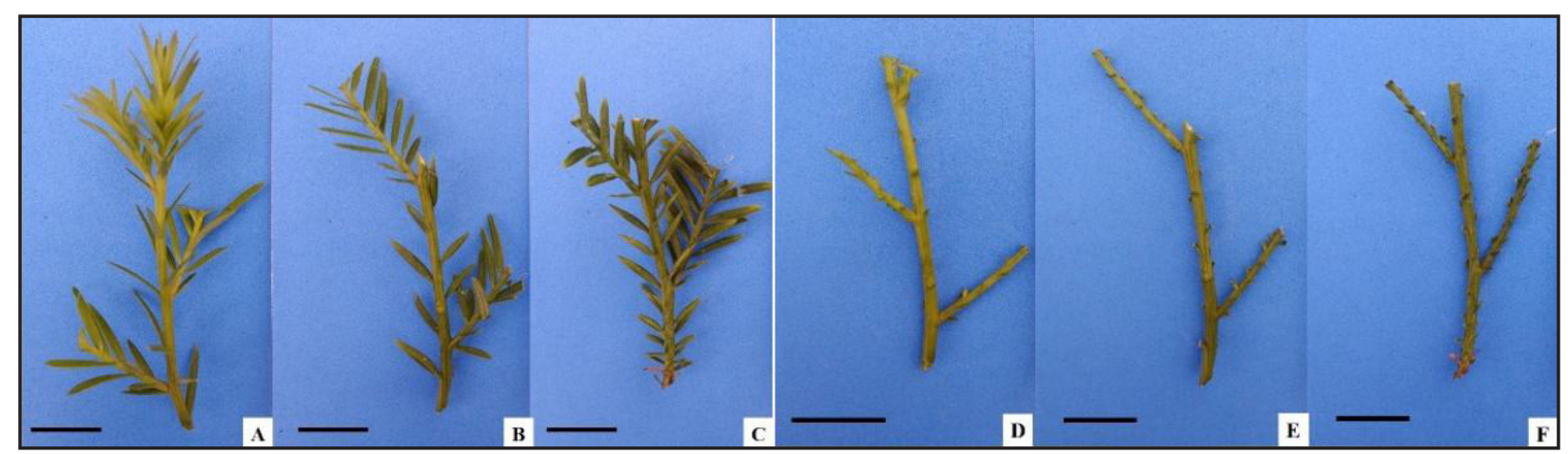

Fonte: Autores (2017)

Em que: *As barras representam $2 \mathrm{~cm}$ de comprimento.

\subsection{Experimento II - avaliação de diferentes clones e substratos}

O experimento foi instalado em delineamento inteiramente casualizado (DIC), em esquema fatorial $3 \times 4$, utilizando-se nove repetições com seis miniestacas cada. O fator A foi composto por três diferentes clones (A113, A140 e A228) e o fator D por quatro substratos (marcas comerciais) denominadas no presente trabalho como substrato I, II, III e IV. A caracterização física e química do substrato (Tabela 1) foi determinada no Laboratório de Substratos do Departamento de Horticultura e Silvicultura da Universidade Federal do Rio Grande do Sul, conforme a Instrução Normativa n 17 do Ministério da Agricultura, Pecuária e Abastecimento.

As composições de cada substrato, conforme especificação dos fabricantes, são as seguintes: substrato I - turfa, casca de arroz carbonizada, calcário calcítico, aditivado com N (0,04\%), $\mathrm{P}_{2} \mathrm{O}_{5}(0,04 \%)$ e $\mathrm{K}_{2} \mathrm{O}(0,05 \%)$; substrato II - casca de pinus compostada, casca de arroz carbonizada, fibra de coco, vermiculita, aditivado com calcário $(0,2 \%)$ e 
superfosfato triplo $(0,1 \%)$; substrato III - turfa, vermiculita expandida, casca de pinus e carvão vegetal; substrato IV - turfa de Sphagnum, vermiculita, resíduo orgânico agroindustrial classe A, calcário dolomítico, gesso agrícola e fertilizante NPK (traços).

Tabela 1 - Análise física e química dos substratos utilizados na miniestaquia de Sequoia sempervirens

\begin{tabular}{lcccc}
\hline Atributos analisados & Substrato I & Substrato II & Substrato III & Substrato IV \\
\hline DU $\left(\mathrm{kg} \mathrm{m}^{-3}\right)$ & 614,8 & 515,8 & 651,1 & 282,86 \\
DS $\left(\mathrm{kg} \mathrm{m}^{-3}\right)$ & 292,8 & 226,4 & 392,7 & 133,1 \\
UA (\%) & 52,4 & 56,10 & 39,7 & 52,9 \\
PT (\%) & 84,2 & 89,3 & 78,9 & 87,7 \\
EA (\%) & 20,0 & 39,4 & 25,2 & 31,2 \\
AFD (\%) & 21,3 & 13,02 & 14,20 & 21,2 \\
AT (\%) & 4,7 & 2,0 & 3,7 & 4,4 \\
AR (\%) & 38,2 & 34,84 & 35,9 & 30,9 \\
CRA10 (\%) & 64,2 & 49,8 & 53,8 & 56,5 \\
CRA50 (\%) & 42,9 & 36,8 & 39,6 & 35,3 \\
CRA100 (\%) & 38,2 & 34,8 & 35,9 & 31,0 \\
pH & 5,6 & 5,69 & 6,46 & 6,26 \\
CE (mS cm $\left.{ }^{-1}\right)$ & 1,39 & 0,26 & 0,27 & 0,11 \\
\hline
\end{tabular}

Fonte: Autores (2017)

Em que: $\mathrm{DU}$ = densidade úmida; $\mathrm{DS}$ = densidade seca; UA = umidade atual; PT = porosidade total; $\mathrm{EA}$ = espaço de aeração; $\mathrm{AFD}$ = água facilmente disponível; $\mathrm{AT}$ = água tamponante; $\mathrm{AR}$ = água remanescente; CRA10, 50 e 100 = capacidade de retenção de água sob sucção a 10, 50 e 100 cm de coluna de água; $\mathrm{pH}$ = potencial hidrogeniônico; $\mathrm{CE}$ = condutividade elétrica.

Os clones selecionados para o estudo tiveram suas brotações seccionadas e procedeu-se o preparo das miniestacas, cada uma com aproximadamente dez cm de comprimento. A porção basal foi cortada em bisel e a porção superior incisada transversalmente, mantendo-se um par de folhas aciculares cortadas pela metade. Estas foram dispostas para enraizar em tubetes de $180 \mathrm{~cm}^{3}$, contendo o substrato definido conforme o tratamento, adicionando-se $6 \mathrm{~g} \mathrm{~L}^{-1}$ de fertilizante de liberação controlada (18-05-09) com 5-6 meses de liberação. 
Pereira, M. O.; Navroski, M. C.; Ângelo, A. C.; Schafer, G.; Andrade, R. S.; Moraes, C.; Souza, G. | 1266

\subsection{Experimento III - concentrações de AIB no enraizamento de miniestacas}

Foi utilizado o clone A228, sendo o experimento conduzido em delineamento inteiramente casualizado (DIC), com seis tratamentos, compostos pelas diferentes concentrações de AIB em mg L-1 (0,0; 1000; 2000; 3000; 4000 e 5000). Foram utilizadas 11 repetições de 10 miniestacas cada. As miniestacas tiveram sua base imersa em soluções hidroalcoólicas (50\% v/v) com diferentes concentrações de AIB, permanecendo em contato com a solução por um período de 20 segundos. Foi utilizado o substrato comercial à base de turfa, casca de arroz carbonizada, calcário calcítico - substrato I (Tabela 1) adicionando-se $6 \mathrm{~g} \mathrm{~L}^{-1}$ de fertilizante de liberação controlada (18-05-09) com 5-6 meses de liberação.

\subsection{Condições de cultivo, variáveis e análise estatística}

As bandejas contendo os tubetes com as miniestacas foram acondicionadas em estufim de cobertura plástica (estrutura apresentando 8,0 m de comprimento $\mathrm{x}$ 1,20 $\mathrm{m}$ de largura $\times 0,9 \mathrm{~m}$ de altura). A temperatura no interior do estufim variou entre $20-32^{\circ} \mathrm{C}$ e a umidade relativa do ar manteve-se superior a $80 \%$, sendo a irrigação realizada por microaspersão durante cinco minutos, cinco vezes por dia. As miniestacas permaneceram nesta condição por 90 dias, momento em que foi realizada a avaliação do experimento.

Nos três experimentos, avaliou-se a porcentagem de sobrevivência; porcentagem de miniestacas que apresentavam calos; porcentagem de miniestacas enraizadas e número de raízes emitidas por miniestaca enraizada. Foram consideradas sobreviventes as miniestacas que apresentavam lenho vivo, folhas velhas ou brotações jovens, enraizadas ou não. Para calos foram consideradas as miniestacas vivas, com formação de massa celular indiferenciada na base, enraizadas ou não. A porcentagem de enraizamento foi considerada sobre o total, não somente sobre as miniestacas sobreviventes. Consideraram-se como enraizadas aquelas com indução de primórdios radiculares de no mínimo 1,0 mm de comprimento. 
Após a verificação da normalidade dos dados por meio do teste de KolmogorovSmirnov e da homogeneidade pelo teste de Bartlett, realizou-se a análise de variância. Quando necessário, os dados foram transformados pela função $(x+0,5)^{0,5}$ e as médias foram comparadas pelo teste de Scott-Knott, a 5\% de probabilidade. Para as análises foi utilizado o pacote estatístico SISVAR (FERREIRA, 2011).

\section{RESULTADOS E DISCUSSÃO}

\subsection{Experimento I - padrão de miniestacas}

Miniestacas pouco lignificadas (obtidas do ápice) e com presença de folhas aciculares apresentaram maior percentagem de sobrevivência (95,7\%) (Tabela 2), havendo interação entre o grau de lignificação e a presença de folhas para esta variável. Já para a formação de calos, não houve efeito significativo para nenhum dos fatores, sendo a média geral de 89\%.

O enraizamento seguiu o mesmo padrão da sobrevivência, em que miniestacas obtidas de tecidos menos lignificados e com presença de folhas aciculares apresentaram melhores resultados. Na utilização de miniestacas de tecidos muito lignificados e sem folhas, houve um enraizamento inferior a 10\%. Miniestacas coletadas da porção intermediária apresentaram grande variação, obtendo-se enraizamento de 74,1\% na presença de folhas e resultado de 16,1\% na ausência destas. Essa mesma tendência foi observada para o número de raízes. Miniestacas originárias do ápice ou da posição intermediária e com a presença de folhas aciculares apresentaram o maior número de raízes, com valores entre 7 a 9 raízes.

Para o padrão das miniestacas de sequoia é visível a importância da manutenção das folhas aciculares, principalmente com média ou baixa lignificação (miniestacas apicais). A maior porcentagem de sobrevivência e enraizamento destas miniestacas pode ser explicada pela maior concentração de auxinas endógenas neste 
Pereira, M. O.; Navroski, M. C.; Ângelo, A. C.; Schafer, G.; Andrade, R. S.; Moraes, C.; Souza, G. | 1268

local (DANTAS et al., 2016), uma vez que este fitormônio é produzido por tecidos meristemáticos e transportado de forma basípeta pelas células parenquimáticas para a base das miniestacas (COSTA et al., 2013). Do mesmo modo, a menor sobrevivência e enraizamento das miniestacas na ausência de folhas aciculares provavelmente se deve à falta de produção de carboidratos resultantes da fotossíntese e das auxinas produzidas nas folhas e gemas apicais, que são essenciais para o enraizamento e, consequentemente, sua sobrevivência (XAVIER; WENDLING; SILVA, 2013). Muitas vezes essas auxinas são suficientes para estimular o enraizamento de estacas apicais, dispensando o uso exógeno.

Tabela 2 - Sobrevivência (\%), enraizamento (\%) e número de raízes de miniestacas de Sequoia sempervirens em função de diferentes padrões de miniestacas (posição/grau de lignificação e presença ou ausência de folhas) obtidas do clone A138

\begin{tabular}{lcccc}
\hline \multirow{2}{*}{ Variável } & $\begin{array}{c}\text { Posição/grau de } \\
\text { lignificação }\end{array}$ & \multicolumn{3}{c}{ Folhas aciculares } \\
\cline { 3 - 5 } Sobrevivência (\%) & Base (lignificada) & $56,1 \mathrm{cA}$ & $20,1 \mathrm{bB}$ & 38,1 \\
& $\begin{array}{c}\text { Intermediário } \\
\text { (média lignificação) }\end{array}$ & $80,4 \mathrm{bA}$ & $24,0 \mathrm{bB}$ & 52,2 \\
& Ápice (pouco lignificada) & $95,7 \mathrm{aA}$ & $71,3 \mathrm{aB}$ & 83,5 \\
\hline & Média & 77,4 & 38,5 & \\
\hline \multirow{2}{*}{ Enraizamento (\%) } & Base (lignificada) & $39,5 \mathrm{cA}$ & $8,7 \mathrm{bB}$ & 24,1 \\
& Intermediário & $74,1 \mathrm{bA}$ & $16,1 \mathrm{bB}$ & 45,1 \\
& (média lignificação) & $94,3 \mathrm{aA}$ & $71,3 \mathrm{aB}$ & 82,8 \\
\hline & Ápice (pouco lignificada) & 69,3 & 32,0 & \\
\hline \multirow{2}{*}{$N^{\circ}$ de raízes } & Média & $3,1 \mathrm{bA}$ & $1,6 \mathrm{bB}$ & 2,3 \\
& Base (lignificada) & $7,4 \mathrm{aA}$ & $2,6 \mathrm{bB}$ & 5,0 \\
\hline & Intermediário & & & \\
\hline & Ápice (pouco lignificada) & $8,8 \mathrm{aA}$ & $6,4 \mathrm{aB}$ & 7,6 \\
\hline
\end{tabular}

Fonte: Autores (2017)

Em que: * Médias seguidas pela mesma letra maiúscula na linha e minúscula na coluna não diferem entre si pelo teste de Scott-Knott, a $5 \%$ de probabilidade de erro. p- valor da interação para sobrevivência: 0,002. CV (\%): 26,6; p- valor da interação para enraizamento: 0,001. CV (\%): 32,2; p- valor da interação para nº de raízes: 0,0017. CV (\%): 22,1. 
Na ausência de folhas aciculares, observou-se uma sobrevivência de 71,3\% utilizando-se miniestacas apicais, porém com valores inferiores à presença de folhas (94,3\%). A utilização de miniestacas muito lignificadas provocou elevada mortalidade, principalmente na ausência de folhas aciculares. Dessa forma, não se recomenda a utilização de miniestacas de galhos muito lignificados, geralmente obtidas da base dos galhos das minicepas. Esse resultado também favorece a operacionalização na confecção das miniestacas, na qual a manutenção das folhas aciculares acelera o processo.

Resultados superiores para o enraizamento de miniestacas apicais ou menos lignificadas também foram obtidos em outras espécies, como em Araucaria angustifolia (WENDLING; STUEPP; ZUFFELLATO-RIBAS, 2016), Cariniana estrellensis (HERNÁNDES et al., 2013), Peltophorum dubium (MANTOVANI et al., 2017) e Piptadenia gonoacantha (HERNÁNDES et al., 2012). Ferreira et al. (2008) verificaram maior enraizamento de estacas apicais de atemoia "Gefner" (Annona cherimola x A. squamosa), relacionando esses resultados com a menor lignificação de ramos apicais, maior quantidade de células meristemáticas e um metabolismo mais ativo em comparação com outros tipos de estacas.

Considerando-se a preparação das miniestacas em um sistema de propagação clonal, o uso de miniestacas apicais é preferível em relação às basais ou intermediárias, principalmente por não haver necessidade de remover o ápice. Essa prática também reduz a possibilidade de formação de brotos múltiplos, reduzindo a necessidade de trabalho na preparação dos propágulos e manejo das miniestacas para formar as mudas (WENDLING; BRONDANI, 2015). Neste estudo também foi possível observar esse comportamento, em que miniestacas apicais originaram mudas com características ortotrópicas e sem brotos múltiplos (Figura 2a) em relação às miniestacas de origem basal ou intermediárias do ramo (Figura 2b). 
Pereira, M. O.; Navroski, M. C.; Ângelo, A. C.; Schafer, G.; Andrade, R. S.; Moraes, C.; Souza, G. | 1270

Figura 2 - a) Miniestaca obtida da porção apical, apresentando crescimento ortotrópico;

b) miniestaca obtida da parte basal, apresentando múltiplas brotações

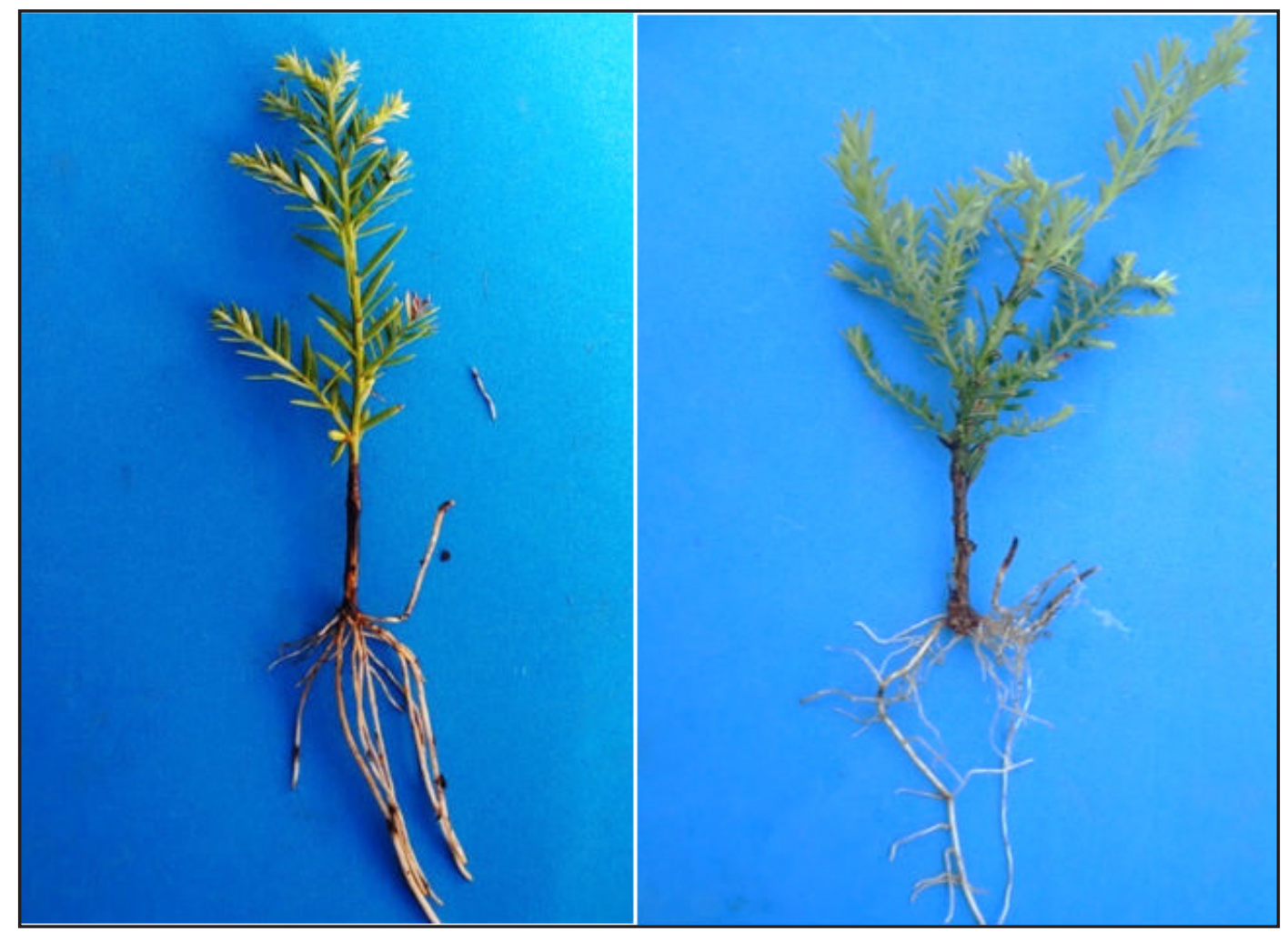

Fonte: Autores (2017)

\subsection{Experimento II - avaliação de diferentes substratos e clones}

Na miniestaquia de sequoia em função do uso de diferentes substratos e clones não houve diferença significativa para nenhum dos fatores relacionados à sobrevivência (média: 97,9\%) e à formação de calos (média: 95,6\%). Já para o enraizamento $(p=0,016)$ e número de raízes ( $p=0,0001)$ houve interação entre os fatores.

Considerando-se todos os clones indistintamente, houve variação nas percentagens de enraizamento para os substratos utilizados, com valores entre 66 e 100\% (Tabela 3). Para os clones A113 e A140, as diferenças entre os substratos não foram significativas, variando entre 84,5 a 100\%. Miniestacas oriundas do clone A228 apresentaram maiores percentagens de enraizamento quando cultivadas nos substratos com maior densidade e menor porosidade, que apresentam composição 
mais orgânica (turfa, casca de pinus, carvão vegetal) (substrato I e III), não havendo diferenças significativas. Os substratos II e IV apresentaram aproximadamente 50\% menos raízes. Silva, Simões e Silva (2012) também destacam os efeitos de diferentes composições de substratos e de suas propriedades físicas e químicas sobre o enraizamento e a qualidade de mudas clonadas, principalmente em clones e/ou espécies difíceis de se propagarem vegetativamente.

O número de raízes foi mais influenciado pelo clone do que pelo substrato utilizado. A média geral para o clone A113 foi 57\% menor que para o clone A140 e 43\% menor que para o clone A228. Para o clone A113, não houve diferença significativa entre os substratos; já para os clones A140 e A228, o número de raízes mostrou diferenças estatísticas entre os substratos. Independentemente dos clones estudados, o substrato III apresentou a maior formação de raízes, sendo 35\% melhor que o substrato II, que apresentou os menores valores.

Tabela 3 - Enraizamento (\%) e número de raízes em miniestacas de Sequoia sempervirens em função dos diferentes clones e substratos utilizados

\begin{tabular}{cccccc}
\hline \multirow{2}{*}{ Variável } & Substrato & \multicolumn{3}{c}{ Clone } & \multirow{2}{*}{ Média } \\
\cline { 3 - 4 } & Substrato I & A113 & A140 & A228 & \\
\hline & Substrato II & $84,0 \mathrm{aA}$ * & $100,0 \mathrm{aA}$ & $93,3 \mathrm{aA}$ & 94,4 \\
& Substrato III & $94,4 \mathrm{aA}$ & $97,8 \mathrm{aA}$ & $67,8 \mathrm{bB}$ & 76,1 \\
Enraizamento (\%) & Substrato IV & $92,1 \mathrm{aA}$ & $90,0 \mathrm{aA}$ & $66,7 \mathrm{bB}$ & 82,9 \\
& Média & 90,2 & 96,6 & 81,4 & \\
& Substrato I & $4,7 \mathrm{aB}$ & $10,5 \mathrm{bA}$ & $9,8 \mathrm{bA}$ & 8,3 \\
& Substrato II & $4,0 \mathrm{aB}$ & $11,4 \mathrm{aA}$ & $4,8 \mathrm{cB}$ & 6,7 \\
& Substrato III & $5,2 \mathrm{aB}$ & $13,1 \mathrm{aA}$ & $12,5 \mathrm{aA}$ & 10,3 \\
& Substrato IV & $4,9 \mathrm{aB}$ & $9,5 \mathrm{bA}$ & $6,1 \mathrm{cB}$ & 6,8 \\
& Média & 4,7 & 11,1 & 8,3 & \\
\hline
\end{tabular}

Fonte: Autores (2017)

Em que: * Médias seguidas pela mesma letra minúscula na coluna e maiúscula na linha não diferem entre si pelo teste de Scott-Knott, a 5\% de probabilidade de erro. ${ }^{\text {ns }}$ - não significativo a $5 \%$ de probabilidade de erro. CV\% enraizamento: 17,3; CV\% número de raízes: 28,9. 
Pereira, M. O.; Navroski, M. C.; Ângelo, A. C.; Schafer, G.; Andrade, R. S.; Moraes, C.; Souza, G. | 1272

Ao contrário do que é recomendado na miniestaquia para várias espécies florestais, como Piptocarpha angustifolia (STUEPP et al., 2016); Eucalyptus urophylla x E. grandis (SILVA; SIMÕES; SILVA, 2012) e Ilex paraguariensis (KRATZ et al., 2015), o clone A228 da Sequoia sempervirens não se adaptou (Tabela 3) a compostos leves e com elevada porosidade, com a presença de fibra de coco, vermiculita e turfa de Sphagnum (Tabela 1). Esses componentes têm sido cada vez mais utilizados na composição de substratos para propagação vegetativa de plantas, proporcionando excelente drenagem, boa oxigenação de raízes, estabilidade estrutural relativa e baixa densidade (CALDEIRA et al., 2013). Contudo, diferenças podem ocorrer entre as espécies e clones, como observado neste estudo. Para Piptadenia gonoacantha, as maiores médias de sobrevivência e enraizamento de estacas foram obtidas quando cultivadas no substrato composto por material orgânico (HERNÁNDES et al., 2012), corroborando os resultados obtidos para o clone A228.

Outro fator facilmente observado é o efeito clonal na formação de raízes, no qual o clone A113 apresentou resultados bem inferiores aos demais clones, independentemente do substrato utilizado. Esse resultado confirma a hipótese de Assis e Teixeira (1999) de que o genótipo é um dos fatores que influenciam o enraizamento e que há uma grande variação entre espécies, cultivares e clones em relação à maior ou menor habilidade natural para formar raízes. Resultados semelhantes foram encontrados em Castanea sativa (DANTAS et al., 2016) e Acacia mearnsii (ENGEL et al., 2017), cujo enraizamento é variável em função de clones ou genótipos.

O substrato tem papel fundamental no enraizamento adventício, não tendo apenas a função de suporte, devendo também apresentar características que favoreçam o desenvolvimento radicular. Contudo, o sucesso da propagação por miniestaquia não é determinado apenas pelo substrato utilizado, dependendo também de diversos outros fatores, tais como: controle das condições ambientais no local de propagação, tipos de miniestacas, nutrição das minicepas (DIAS et al., 2015) e resposta do material genético ao enraizamento adventício. 


\subsection{Experimento III - concentrações de AIB no enraizamento de miniestacas}

A utilização de AIB na miniestaquia de sequoia não apresentou diferença significativa em nenhuma das variáveis avaliadas. A sobrevivência das miniestacas apresentou média de $92 \%$, variando entre $88 \%$ e $95 \%$. O enraizamento apresentou média de $89 \%$, com baixa variação entre os tratamentos, ficando entre $87 \%$ e $91 \%$. A formação de calos foi elevada, com média de 95\%. Foram encontradas em média 5,6 raízes por miniestaca.

A ausência de efeito significativo da auxina AIB no enraizamento das miniestacas pode indicar que esta espécie apresenta um elevado potencial rizogênico natural. Condições fisiológicas adequadas para a iniciação radicial também podem ter sido induzidas pelo sistema de cultivo em minijardim clonal, que favorece a formação de brotos rejuvenescidos e revigorados e pela nutrição fornecida. Resultados semelhantes foram observados por Mantovani et al. (2017), trabalhando com Peltophorum dubium e em outras coníferas, como: Pinus patula (APARICIO-RENTERÍA et al., 2014) Pinus pinaster (MAJADA et al., 2011), e Taxodium distichum (KING; ARNOLD; WELSH, 2011). Em muitos casos, a aplicação de AIB pode ter uma influência indireta, aumentando a velocidade de translocação e movimento de carboidratos para a base de estacas e, consequentemente, estimulando o enraizamento.

\section{CONCLUSÕES}

Miniestacas apicais e com presença de folhas aciculares apresentaram maior sobrevivência, enraizamento e número de raízes, além de uma melhor formação das mudas.

Os clones A113 e A140 não apresentaram diferença na porcentagem de enraizamento com os substratos testados. O clone A228 obteve maior porcentagem de enraizamento e número de raízes, utilizando-se substratos com maior densidade e composição mais orgânica.

A utilização de AIB não proporcionou um acréscimo no enraizamento das miniestacas para o clone testado, não sendo recomendado o seu uso. 
Pereira, M. O.; Navroski, M. C.; Ângelo, A. C.; Schafer, G.; Andrade, R. S.; Moraes, C.; Souza, G. | 1274

\section{REFERÊNCIAS}

ALCANTARA, G. B. et al. Efeito da idade da muda e da estação do ano no enraizamento de miniestacas de Pinus taeda L. Revista Árvore, Viçosa, MG, v. 31, n. 3, p. 399-404, 2007.

APARICIO-RENTERÍA, A. et al. Propagación por enraizamiento de estacas y conservación de árbolesplus extintos de Pinus patula procedentes del norte de Veracruz, México. Madera y Bosques, Xalapa, n. 20, p. 85-96, 2014.

ASSIS, T. F.; TEIXEIRA, S. L. Enraizamento de plantas lenhosas. In: TORRES, A. C.; CALDAS, L. S.; BUSO, J. A. Cultura de tecidos e transformação genética de plantas. Brasília: Embrapa-SPI; Embrapa-CNPH, 1999. p. 261-296.

BOE, K. N. Sequoia sempervirens (D. Don) Endl. In: SCHOPMEYER, C. S. (ed.). Seeds of woody plants in the United States. Washington: USDA Forest Service, 1974. p. 764-766. (Agriculture Handbook, 450).

CALDEIRA, M. V. W. et al. Substratos alternativos na produção de mudas de Chamaecrista desvauxii. Revista Árvore, Viçosa, MG, v. 37, p. 31-39, 2013.

COSTA, C. T. et al. When stress and development go hand in hand: main hormonal controls of adventitious rooting in cuttings. Frontiers in Plant Science, [s. I.], v. 4, p. 1-19, 2013.

DANTAS, A. K. et al. Rooting of minicuttings of Castanea sativa Mill. hybrid clones. Revista Árvore, Viçosa, MG, v. 40, n. 3, p. 465-475, 2016.

DIAS, P. C. et al. Tipo de miniestaca e de substrato na propagação vegetativa de angicovermelho (Anadenanthera macrocarpa (Benth.) Brenan). Ciência Florestal, Santa Maria, v. 25, n. 4, p. 909-919, 2015.

ENGEL, M. L. et al. Enraizamento de miniestacas de diferentes clones de Acacia mearnsii De Wildeman com aplicação de AIB. Revista Espacios, Caracas, v. 38, n. 23, 2017.

FERREIRA, D. F. Sisvar: a computer statistical analysis system. Ciência e Agrotecnologia, Lavras, v. 35, n. 6, p. 1039-1042, 2011.

FERREIRA, G. et al. Enraizamento de estacas de atemoieira 'Gefner' tratadas com auxinas. Revista brasileira de fruticultura, Jaboticabal, v. 30, p. 1083-1088, 2008.

HARTMANN, H. T. et al. Plant propagation: principles and practices. 8th ed. New Jersey: Prentice Hall, 2011. 915 p.

HERNÁNDES, W. et al. Propagação vegetativa de pau-jacaré (Piptadenia gonoacantha (MART.) MACBR.) por estaquia. Revista Árvore, Viçosa, v. 36, n. 5, p. 813 - 823, 2012.

HERNÁNDES, W. et al. Propagação vegetativa do jequitibá-rosa (Cariniana estrellensis (Raddi) Kuntze) por estaquia. Revista Árvore, Viçosa, MG, v. 37, n. 5, p. 955-967, 2013.

KING, A. R. M. A.; ARNOLD, D. F.; WELSH; W. T. Substrates, wounding, and growth regulator concentrations alter adventitious rooting of Baldcypress cuttings. Hort Science, São José, $n$. 46, p. 1387-1393, 2011. 
KRATZ, D. et al. Produção de mudas de erva-mate por miniestaquia em substratos renováveis. Revista Floresta, Curitiba, v. 45, p. 609-616, 2015.

LUNA, T. Vegetative propagation of coast alredwood (Sequoia sempervirens (Lamb. ex D. Don) Endl.). Native Plants Journal, Washington, v. 9, n. 1, p. 25-28, 2008.

MAJADA, J. et al. Mini-cuttings: an effective technique for the propagation of Pinus pinaster Ait. New Forests, Dordrecht, n.41, p. 399-412, 2011.

MANTOVANI, N. et al. Cultivo de canafístula (Peltophorum dubium) em minijardim clonal e propagação por miniestacas. Revista Ciência Florestal, Santa Maria, v. 27, n. 1, p. 225-236, 2017.

OLIVEIRA, T. P. F. et al. Aplicação de AIB e tipo de miniestacas na produção de mudas de Handroanthus heptaphyllus Mattos. Ciência Florestal, Santa Maria, v. 26, n. 1, p. 313-320, 2016.

OLIVEIRA, Y. et al. Substratos, concentrações de ácido indolbutírico e tipos de miniestacas no enraizamento de melaleuca (Melaleuca alternifolia Cheel). Revista Brasileira de Plantas Medicinais, Paulinia, v. 14, n. 4, p. 611-616, 2012.

OLSON, D. F.; ROY, D. F.; WALTERS, G. A. Sequoia sempervirens (D. Don) Endl, redwood. In: BURNS, R. M.; HONKALA, B. H. (ed.). Silvics of North America. [S. I.]: U.S. Department of Agriculture, 1990. p. 541-551. (Agricultural Handbook, v. 1).

PIMENTEL, N. et al. Shoot segment and substrate composition in rooting of juvenile ipe-roxo mini-cuttings. Ciência Rural, Santa Maria, v. 46, n. 6 p. 996-1002, 2016.

SILVA, R. B. G.; SIMÕES, D.; SILVA, M. R. Qualidade de mudas clonais de Eucalyptus urophyllax E. grandis em função do substrato. Revista Brasileira de Engenharia Agrícola e Ambiental, Campina Grande, v. 16, p. 297-302, 2012.

STUEPP, C. A. et al. Quality of clonal plants of Piptocarpha angustifolia in different renewable substrates and seasons of the year. Pesquisa Agropecuária Brasileira, Brasília, v. 51, n. 11, p. 1821-1829, 2016.

UNITED STATES. Department of Agriculture. Wood Handbook: Wood as an Engineering Material. [s. I.]: Forest Products Laboratory General Technical Report FPL-GTR-190, 2010. 509 p.

XAVIER, A.; WENDLING, I.; SILVA, R. L. Silvicultura clonal: princípios e técnicas. 2. ed. Viçosa, MG: Universidade Federal de Viçosa, 2013. 280 p.

WENDLING, I.; BRONDANI, G. Vegetative rescue and propagation of Araucaria angustifolia. Revista Árvore, Viçosa, MG, v. 39, n. 1, p. 93-104, 2015.

WENDLING, I.; STUEPP, C. A.; ZUFFELLATO-RIBAS, K. C. Rooting of Araucaria angustifolia: types of cuttings and stock plants sex. Revista Árvore, Viçosa, MG, v. 40, n. 6, p. 1013-1021, 2016. 
Pereira, M. O.; Navroski, M. C.; Ângelo, A. C.; Schafer, G.; Andrade, R. S.; Moraes, C.; Souza, G. | 1276

\section{Contribuição de Autoria}

\section{1 - Mariane de Oliveira Pereira}

Engenheira Florestal, Dra., Pós-Doutora

https://orcid.org/0000-0001-5518-7464•maripereira.florestal@gmail.com

Contribuição: Conceituação, Investigação, Metodologia, Administração do projeto, Visualização de dados, Escrita - primeira redação

\section{2 - Marcio Carlos Navroski}

Engenheiro Florestal, Professor

https://orcid.org/0000-0002-2645-9763•marcio.navroski@udesc.br

Contribuição: Conceituação, Investigação, Metodologia, Software, Supervisão, Visualização de dados, Escrita - revisão e edição

\section{3 - Alessandro Camargo Ângelo}

Engenheiro Florestal, Dr., Professor

https://orcid.org/0000-0003-3435-300X•alessandrocangelo@gmail.com

Contribuição: Metodologia, Supervisão

\section{4 - Gilmar Schafer}

Engenheiro Agrônomo, Dr., Professor

https://orcid.org/0000-0003-1422-5051•schafer@ufrgs.br

Contribuição: Metodologia

\section{5 - Ramon Silveira de Andrade}

Engenheiro Florestal, Mestrando em Engenharia Florestal https://orcid.org/0000-0001-6429-3947•ramon.andrade@edu.udesc.br Contribuição: Investigação, Metodologia, Visualização de dados

\section{6 - Carolina Moraes}

Graduandada do Curso de Engenharia Florestal https://orcid.org/0000-0001-9936-1110•carolina.moraes1@edu.udesc.br Contribuição: Investigação, Metodologia 


\section{7 - Gabriel de Souza}

Graduandado do Curso de Engenharia Florestal

https://orcid.org/0000-0002-8732-7262•gaabrieel_soouzaa@hotmail.com

Contribuição: Investigação, Metodologia

\section{Como citar este artigo}

Pereira, M. O.; Navroski, M. C.; Ângelo, A. C.; Schafer, G.; Andrade, R. S.; Moraes, C.; Souza, G. Enraizamento de Sequoia sempervirens (Cupressaceae) em função do padrão de miniestacas, substratos e regulador de crescimento. Ciência Florestal, Santa Maria, v. 31, n. 3, p. 1258-1277, 2021. DOI 10.5902/1980509836857. Disponível em: https://doi.org/10.5902/1980509836857. Acesso em: xx mês-abreviado. 2021. 